\title{
Dongping Song: Container Logistics and Maritime Transport
}

\section{Routledge, New York, 2021. pp. 400, ISBN: 9780429320996}

\section{Gang Chen ${ }^{1}$}

Published online: 6 September 2021

(c) World Maritime University 2021

Container logistics chains connect the global economies and act as a catalyst for international trade. The chain is a highly complex system and requires sophisticated analytical tools to achieve an efficient and effective logistics service. In the related literature, most books address this industry from the perspective of management, strategy, or policy-making, and there seems to be a lack of monographs dealing with analytical methods and tools for optimising the container logistics operations. Existing operation studies are typically geared towards individual and/or specific issues that are published largely as journal articles. It is thus a challenge to consolidate those scattered studies into a comprehensive and coherent monograph, due to the wide disciplinary span of their solution methods. In that sense, this book fills in the gap of the domain. It presents state-of-art optimization models and methods capable of dealing with the strategic, tactical, and operational planning problems associated with almost all the main segments of container logistics.

The book first provides an overall introduction to the background of container logistics in Chapters 1 and 2. It explains the conceptual relationships between international trade, maritime transport, maritime logistics, and container shipping supply chain, as well as the logistics performance and value creation. This overview enables readers to better understand 'Operations Management' in container shipping supply chain (CSSC) and build a cross-disciplinary connection with 'Operations Research' studies in the later chapters. The book then addresses the key planning problems in four main segments of CSSC, i.e. freight logistics, container logistics, vessel logistics, and port/terminal management. Each segment is studied using both qualitative/ descriptive analytics and quantitative/prescriptive analytics. More specifically,

- The freight logistics segment is briefly presented in Chapter 3, with a focus on the shipment routing problem and its solution methods.

Gang Chen

gc@wmu.se

1 World Maritime University, Malmö, Sweden 
- Chapter 4 provides in-depth studies on container logistics, which is the logistics of container boxes in a narrow sense. It starts with a discussion of containerization and explains the reasons for empty container repositioning (ECR) and then presents various strategies for ECR planning and two modelling techniques. A few specific mathematical ECR models are presented for in-depth discussions.

- Chapter 5 addresses the logistics of container vessels at strategical, tactical, and operational levels. It first describes the liner shipping basics and explains the key planning problems using examples and then conducts detailed discussions based on quantitative analytics. A wide range of problems are covered including horizontal competition and cooperation, vertical integration with port, service network design, ship scheduling, speed optimization, slow steaming, and disruption management.

- Port and terminal management is studied in Chapter 6. Inter-port competition is discussed using game theory; then, port sub-systems are addressed individually including quay, yard, and landside. Different approaches to integrate and coordinate the sub-system planning and to mitigate the terminal congestion are also presented.

- Lastly, environmental sustainability issues and related solutions are discussed in Chapter 7, covering sulphur emission, carbon emissions, decarbonization strategies, and emission reduction measures by ships and by ports. To overcome the fragmentation in liner shipping, multi-objective optimization is discussed to compromise different stakeholder interests.

Several features distinguish this book from others. First, it does holistically cover all the key operation planning problems of container shipping logistics using a coherent and systematic approach. Second, it combines qualitative analytics with quantitative ones so as to provide a holistic study on each problem and manages to explain the profound complexities in a very simple language. Third, it offers a broad spectrum of methods, including mathematical modelling, optimization, discrete event simulation, metaheuristics, agent-based simulation, multiple agent system, and game theory. Fourth, the book is enriched by a number of examples, generic models, and case studies with in-detail descriptions and analysis. Lastly, the book chooses to focus on the maritime perspective having taken the inland transport out of the scope. Being an indispensable segment of CSSC, the latter one shows significant impact of disruption propagation, especially during the recent COVID-19 pandemic. For strengthening CSSC resilience, it seems necessary to bring inland transport segment into the whole picture.

Overall, this book provides a comprehensive and in-depth view of CSSC operation planning problems. It is an admirable achievement to cover such a wide range of topics and to provide solution approaches in a multi-disciplinary way. Being a significant contribution to the CSSC field, the book is highly recommended to advanced students, researchers, industry professionals, and of course academics in the field.

Publisher's note Springer Nature remains neutral with regard to jurisdictional claims in published maps and institutional affiliations. 